\title{
Subterranean movement inferred by temporary emigration in Barton Springs salamanders (Eurycea sosorum)
}

Nathan F Bendik $^{\text {Corresp., } 1}$, Dee Ann Chamberlain ${ }^{1}$, Thomas J Devitt ${ }^{1,2}$, Sarah E Donelson ${ }^{1}$, Bradley Nissen ${ }^{1,3}$, Jacob D Owen $^{1,4}$, Donelle Robinson ${ }^{1,5}$, Blake N Sissel ${ }^{1,6}$, Kenneth Sparks ${ }^{1,7}$

${ }^{1}$ Watershed Protection Department, City of Austin, Austin, Texas, United States of America

2 University of Texas, Department of Integrative Biology and Biodiversity Center, Austin, Texas, United States of America

3 Tennessee State University, Department of Agricultural and Environmental Sciences, Nashville, Tennessee, United States of America

4 Randolph Air Force Base, AFCEC, JBSA ISS Natural Resource Support, San Antonio, Texas, United States of America

5 United States Fish and Wildlife Service, Austin Ecological Services Field Office, Austin, Texas, United States of America

6 Travis County, Department of Transportation and Natural Resources, Austin, Texas, United States of America

7 Baer Engineering \& Environmental Consulting, Inc., Austin, Texas, United States of America

Corresponding Author: Nathan F Bendik

Email address: nathan.bendik@austintexas.gov

Movement behavior is an important aspect of animal ecology but is challenging to study in species that are unobservable for some portion of their lives, such as those inhabiting subterranean environments. Using four years of robust-design capture-recapture data, we examined the probability of movement into subterranean habitat by a population of endangered Barton Springs salamanders (Eurycea sosorum), a species that inhabits both surface and subterranean groundwater habitats. We tested the effects of environmental variables and body size on survival and temporary emigration, using the latter as a measure of subterranean habitat use. Based on 2,046 observations of 1,578 individuals, we found that temporary emigration was higher for larger salamanders, $79 \%$ of which temporarily emigrated into subterranean habitat between primary sampling intervals, on average. Body size was a better predictor of temporary emigration and survival compared to environmental covariates, although coefficients from lower ranked models suggested turbidity and dissolved oxygen may influence salamander movement between the surface and subsurface. Surface population dynamics are partly driven by movement below ground and therefore surface abundance estimates represent a fraction of the superpopulation. As such, while surface habitat management remains an important conservation strategy for this species, periodic declines in apparent surface abundance do not necessarily indicate declines of the superpopulation associated with the spring habitat. 
1 Subterranean movement inferred by temporary emigration in Barton

4 Nathan F. Bendik, Dee Ann Chamberlain, Thomas J. Devitt ${ }^{1}$, Sarah E. Donelson, Bradley

5 Nissen $^{2}$, Jacob D. Owen ${ }^{3}$, Donelle Robinson ${ }^{4}$, Blake N. Sissel ${ }^{5}$, Kenneth Sparks ${ }^{6}$

7 Watershed Protection Department, City of Austin, Austin, Texas, U.S.A.

8 'Present address: Department of Integrative Biology and Biodiversity Center, University of

9 Texas, Austin, TX, USA

$10{ }^{2}$ Present address: Department of Agricultural and Environmental Sciences, Tennessee State

11 University, Nashville, TN, USA

12 '3resent address: AFCEC, JBSA ISS Natural Resource Support, Randolph AFB, TX, USA

13 4Present address: Austin Ecological Services Field Office, United States Fish and Wildlife

14 Service, Austin, TX, USA

15 5Present address: Department of Transportation and Natural Resources, Travis County, Austin, 16 Texas, USA

17 'Present address: Baer Engineering \& Environmental Consulting, Inc., Austin, TX, USA

19 Corresponding Author:

20 Nathan F. Bendik

21505 Barton Springs Rd., Watershed Protection Department, $11^{\text {th }}$ Floor, Austin, TX 78704

22 Email address: nathan.bendik@austintexas.gov

\section{Abstract}

Movement behavior is an important aspect of animal ecology but is challenging to study in species that are unobservable for some portion of their lives, such as those inhabiting subterranean environments. Using four years of robust-design capture-recapture data, we examined the probability of movement into subterranean habitat by a population of endangered Barton Springs salamanders (Eurycea sosorum), a species that inhabits both surface and subterranean groundwater habitats. We tested the effects of environmental variables and body size on survival and temporary emigration, using the latter as a measure of subterranean habitat use. Based on 2,046 observations of 1,578 individuals, we found that temporary 
32 emigration was higher for larger salamanders, $79 \%$ of which temporarily emigrated into subterranean

33 habitat between primary sampling intervals, on average. Body size was a better predictor of temporary

34 emigration and survival compared to environmental covariates, although coefficients from lower ranked

35 models suggested turbidity and dissolved oxygen may influence salamander movement between the

36 surface and subsurface. Surface population dynamics are partly driven by movement below ground and

37 therefore surface abundance estimates represent a fraction of the superpopulation. As such, while surface

38 habitat management remains an important conservation strategy for this species, periodic declines in

39 apparent surface abundance do not necessarily indicate declines of the superpopulation associated with

40 the spring habitat.

41

\section{Introduction}

43

Amphibians are declining in many parts of the world owing to numerous factors (Lannoo 2005, Catenazzi 2015, Grant et al. 2016). Studies linking movement patterns to underlying behavioral and ecological mechanisms (Nathan et al. 2008) are needed to better understand amphibian population declines (Pittman et al. 2014). Tracking individual movement and fate has been suggested as a way to close this information gap by directly linking fitness consequences of movement to management strategies or environmental conditions (Bailey and Muths 2019). Although appealing, this approach requires radio telemetry (Bailey and Muths 2019), which is impractical for many amphibians because they are too small to be fitted with transmitters. Indirect assessments of movement behavior are often more practical for many amphibians (e.g., capture-recapture studies; Marsh et al. 2005, Lowe et al. 2006, Ringler et al. 2009, Cayuela et al. 2020), including fossorial or cave-dwelling species (Balázs et al. 2020).

Many salamander species use subterranean habitat because it provides environmental conditions that are relatively stable compared to surface habitats. Some species are obligate residents of caves with highly specialized adaptations (troglobites), while others are facultative troglophiles that periodically venture underground (Gorički et al. 2019). Studies of these populations are challenging because individuals are difficult or impossible to observe directly. Because of access restrictions to cave habitats, high levels of endemicity (Culver et al. 2000, Trontelj et al. 2009), and apparent rarity (Krejca and Weckerly 2007, Jugovic et al. 2015, DiStefano et al. 2020), answering basic ecological questions (e.g., Who lives there? How many are there?) remains a fundamental challenge for the study of cave-dwelling animals (Wynne et al. 2019). Cave-dwelling vertebrates are typically observed only in relatively small portions of their habitat, where humans can enter or remotely access their environment. Sampling generally occurs in human-accessible caves or through "windows" into their environment such as wells or spring outlets (Miller and Niemiller 2008, Graening et al. 2010, Day et al. 2016, Niemiller et al. 2016, Phillips et al. 
2017, Krejca and Reddell 2019). Moreover, many cave-adapted species are of conservation concern because of their high endemicity and the sensitivity of subterranean habitats to disturbance and pollution (Chippindale and Price 2005, Miller and Niemiller 2008, Fenolio et al. 2013, Devitt et al. 2019, Gorički et al. 2019), underscoring the need for basic research on the biology of subterranean fauna (Mammola et al. 2019).

Studies of cave organisms have relied mostly on capture-recapture data to make inferences about their movement behavior (Means and Johnson 1995, Trajano 1997, Lopes Ferreira et al. 2005, Băncilă et al. 2018, Balázs et al. 2020). Direct observations of recaptured individuals have been used to quantify movement patterns where habitat is accessible (Means and Johnson 1995, Trajano 1997, Balázs et al. 2020). Where animals retreat to inaccessible habitat, e.g., from a cave stream or spring outlet to the aquifer that feeds it, capture-recapture data may indicate immigration to or emigration from these areas (Means and Johnson 1995, Day et al. 2016). Explicitly modeling transitions between observable and unobservable states using capture-recapture data (so-called temporary emigration) allows for estimates of demographic parameters (Kendall et al. 1997), breeding status (e.g., Kendall and Bjorkland 2001), habitat use (Bailey et al. 2004a, Cecala et al. 2013), and movement (Băncilă et al. 2018). A temporary emigration model provides estimates of movement into and out of the sample area based on the transition rate between observable and unobservable states (Kendall et al. 1997). In cases where observable states correspond to accessible areas (e.g., within a cave gallery or at a spring outlet), quantifying temporary emigration allows inferences about the characteristics of the population that use both the accessible and inaccessible areas rather than being limited to only the area directly sampled.

Barton Springs salamanders (Eurycea sosorum) occur in both surface and subterranean habitat, but populations are typically only accessible for study near springs. When first described, the salamanders were assumed to be restricted to the immediate vicinity of Barton Springs in Austin, Texas (Chippindale et al. 1993), one of several large spring complexes in the Edwards Aquifer of central Texas that harbors endemic species (Bowles and Arsuffi 1993; Krejca and Reddell, 2019). Because the subterranean conduits feeding Barton Springs are largely inaccessible, biologists questioned whether the species was primarily a surface dweller that occasionally enters subterranean habitat or an obligate subterranean species that is flushed to the surface accidentally (Sweet 1978, Chippindale et al. 1993). Following its description, in 1997 this species was listed as endangered under the US Endangered Species Act of 1973 due to its exceptionally small range (at the time, known from only three springs in a city park) and presumed low abundances (Chippindale et al. 1993, City of Austin 1997, U.S. Fish and Wildlife Service 1997). Although additional occurrences of this species have subsequently been recorded outside of the type locality (Bendik et al. 2013a, McDermid et al. 2015, Devitt and Nissen 2018), abundances at those 
98

sites are lower and surface habitat is more limited in extent compared to Barton Springs. Abundances can be high at the type locality (e.g., > 500 individuals) but may fluctuate by orders of magnitude and occasionally reach zero, or nearly so (Bendik and Dries 2018, Dries and Colucci 2018). This suggests that either surface populations are occasionally extirpated and recolonized from subterranean populations or that emigration from the surface to the aquifer is occurring (Bendik and Dries 2018). Complete extirpation without emigration into the aquifer would suggest that the surface habitat is a population sink (i.e., unable to be maintained without immigration; Pulliam 1988) and that surface populations could be a dead-end in terms of species persistence. If so, changes to population management practices and recovery planning may be necessary, because a primary focus of conservation for Barton Springs salamanders includes management and restoration of the surface habitat (Dries et al. 2013, U.S. Fish and Wildlife Service 2016).

Here, we report the results of a four-year robust-design capture-recapture study to better understand movement patterns and subterranean habitat use of Barton Springs salamanders. We examined how extrinsic environmental factors (spring discharge, turbidity, dissolved oxygen, temperature) and intrinsic factors (body size) affect survival and temporary emigration. Population dynamics differ between juveniles and adults in Barton Springs salamanders (Bendik and Dries 2018), and size is often correlated with the propensity for movement in amphibians (Cayuela et al. 2020). Similarly, spring flow is an important driver of environmental conditions (e.g., Mahler and Bourgeais 2013) that are important to the ecology and physiology of groundwater Eurycea salamanders (Fries 2002, Woods et al. 2010, Crow et al. 2016, Bendik and Dries 2018) and may influence movement patterns as well.

\section{Materials \& Methods}

\section{Study Site}

We studied Barton Springs salamanders (Figure 1) at Eliza Spring (Figure 2), part of the Barton Springs complex in Austin, Texas, USA. Eliza Spring is adjacent to Barton Springs Pool, a popular spring-fed swimming pool. Barton Springs is the primary discharge point for the Barton Springs segment of the Edwards Aquifer, a sole-source karstic aquifer that responds rapidly to changes in precipitation via a system of sinking streams that occur over a $430 \mathrm{~km}^{2}$ area (Hunt et al. 2019). Eliza Spring emerges into a concrete-bottomed pool $\left(74 \mathrm{~m}^{2}\right)$ with a water depth of approximately $0.3 \mathrm{~m}$ (Figure $2 \mathrm{~A}$ ) and harbors the highest average densities of Barton Springs salamanders among known spring localities $\left(4.32 / \mathrm{m}^{2} \pm 3.4\right.$ SD compared to $\leq 0.25 / \mathrm{m}^{2} \pm 0.3$ at other sites within the Barton Springs complex; Dries and Colucci 2018). Throughout most of our study, the spring pool discharged directly into a concrete pipe (0.6 m 
130 diameter) that flowed to Barton Creek, likely representing a point of no return for salamanders. During

131 the last year of our study, the pipe was replaced by a $1 \mathrm{~m}$ wide overland stream that created $25 \mathrm{~m}^{2}$ of

132 additional habitat, but that still terminated at a concrete tunnel that conveys Barton Creek (Figure 2B).

\section{Data Collection}

134 We used a robust-design sampling scheme (Pollock 1982) that consisted of 15 primary sampling events 135 separated by ca. 3 month (range $=2-6$ mo.) intervals during which the population was assumed to be 136 open to births, deaths, and migration. During each primary sampling event, the population was sampled 137 three times over the course of one week. We assumed the population was closed within each primary 138 sampling event. We performed surveys from October 2014 through November 2018. While observers 139 varied from survey to survey (typically a team of 4-6 people), a core group of 3-4 experienced observers 140 were present during most of our sampling events. All fieldwork was performed under the authority of

141 Texas Parks \& Wildlife scientific permit SPR-0113-006 and U.S. Fish and Wildlife permit TE-839031.

142 During surveys, biologists snorkeled from downstream to upstream, searching for salamanders by

143 visually inspecting and moving all rocky substrate and attempting to capture all observed salamanders

144 using aquarium nets. Salamanders were then temporarily held in flow-through mesh containers in the 145 spring to await processing. Captured salamanders were photographed in a transparent water-filled tray 146 against a $5 \mathrm{~mm}$ grid using a Nikon DSLR and macro lens with two flashes mounted on a custom stand.

147 We measured the body length for all individuals captured to the nearest $0.1 \mathrm{~mm}$ using ImageJ (Rasband 148 1997). Body length was quantified as the mid-vertebral distance from the tip of the snout to the posterior 149 insertion of the hindlimbs. Photographs were then cropped to include just the head, and we used program 150 Wild-ID to identify individuals (Bolger et al. 2012) based on differences in color pattern. We used the R statistical software environment (R Core Team 2020) to generate a matrix of capture histories from WildID output. Photographic identification using this approach has been shown to be more accurate than physical tagging in a similarly patterned species (E. tonkawae; Bendik et al. 2013b). One limitation is that small juveniles cannot be tracked reliably using photographs over periods greater than ca. two months because of changes in pigmentation during growth (Bendik et al. 2013b). For this reason, we excluded individuals $<15.01 \mathrm{~mm}$ in body length (corresponding to ca. $25 \mathrm{~mm}$ in total length) from the capturerecapture analysis. The resulting data set included large juveniles and all adults, based on estimates of a mature size of $22.5 \mathrm{~mm}$ snout-vent length (Chippindale et al. 1993). Photographs in the final data set were visually matched and confirmed as a match or non-match using all 20 candidate matches presented by Wild-ID. To reduce visual matching errors, the photos were matched independently by two people and any conflicts found were investigated and resolved. 
162 Analysis

163 We estimated capture $(p)$ and recapture $(c)$ probabilities, survival $(S)$, temporary emigration $(\gamma)$ and

164 abundance $(N)$ using robust-design capture-recapture models. Capture probability is conditional upon the

165 individuals being available for capture. Temporary emigration refers to the state when individuals in a

166 population are temporarily unavailable for capture and is Markovian when movement from the study is

167 dependent upon the prior state (Kendall et al. 1997). Temporary movement of a salamander out of the

168 sampling area, given that it was present during the previous period is estimated by the parameter $\gamma^{\prime \prime}$.

169 Staying out of the sampling area given that it was not present during the previous period is $\gamma^{\prime}$. When these

170 parameters are equal, temporary movement is considered random. All temporary migrants are part of the

171 superpopulation - the total population of individuals in the sampling area including those temporarily

172 unavailable for capture and those available for capture (Kendall et al. 1997). The survival parameter $S$ is a

173 function of both mortality and permanent emigration. Survival is apparent because the fate of each animal

174 that permanently leaves the study area cannot be known without auxiliary information (e.g., from radio

175 telemetry), and thus mortality and permanent emigration are confounded. Abundance $(N)$ for each period

176 refers to the size of the population available at the surface for capture during sampling. We did not

177 attempt to estimate the size of the superpopulation because this requires data (or assumptions) about the

178 source of new recruits when temporary emigration is Markovian (Wen et al. 2011; Kendall et al. 1997).

179 By quantifying temporary emigration, we can measure the prevalence of subterranean movement of

180 Barton Springs salamanders at Eliza Spring. The bottom of the Eliza Spring pool was filled with concrete

181 in the early 1900 s, except for 22 formed outlets ( 7 in the floor and 15 on the sides) to convey the spring

182 water, so most of the base-level substrate is impenetrable by salamanders except through those outlets.

183 All migrants that eventually return to the surface must have retreated below ground, and this rate can be

184 estimated as temporary emigration using capture-recapture data.

185 Because capture-recapture model sets with multiple parameters can result in hundreds or even thousands

186 of different models when all possible combinations of all parameters and covariates are used, we built our

187 model sets using a stage-based, step-down approach, starting with the most general model of time-

188 variation supported by our data (Lebreton et al. 1992). This most general model let $S$ vary by year (ending

189 in Oct./Nov.) and $\gamma^{\prime \prime}$ and $\gamma^{\prime}$ vary by period. We were unable to successfully fit models including full-time

190 variation of $S$. Proceeding with this structure, we first fit a variety of models (without covariates on

191 survival or emigration parameters) to determine the most parsimonious structure for $p$ and $c$, which

192 included time variation within periods but equal across periods, variation between periods but constant

193 within, full-time variation (different estimates for each individual survey), constant detection, and models

194 where $p=c$ (and aforementioned time structures), for a total of $n=20$ model structures of detection. 
196 In the final model-building stage, we compared models where temporary emigration ( $\gamma^{\prime \prime}$ and $\left.\gamma^{\prime}\right)$ varied over periods or as a function of environmental or individual covariates and models where survival probabilities varied with these same covariates. Specifically, we used five covariates that describe aspects of water quality and quantity measured at Barton Springs: flow (spring discharge rate), change in flow between sampling periods, water temperature, dissolved oxygen (DO) concentration, and turbidity. Increases in flow may help flush additional animals to the surface via drift, but flow may also prompt compensatory movement back into the spring outlets, influencing the rate of temporary migration in either direction. Permanent migration in response to discharge may also be reflected by apparent survival estimates. In general, increasing flow is thought to be beneficial to Barton Springs salamanders, particularly when recovering from drought conditions (Dries and Colucci 2018). Our expectation is that spring flow may have a positive influence on actual survival, but high flow could prompt migration underground, producing an overall negative effect on apparent survival if this migration is permanent. Given the complexity of possible responses, we did not have a strong a priori hypothesis for the direction of the effect of these discharge covariates. Low DO and high temperature negatively affect survival and growth of Barton Springs salamanders under laboratory conditions (Woods et al. 2010; Crow et al. 2016), but these conditions infrequently occur in the wild, so we generally expect DO and temperature to have a positive influence on survival. Periods of high turbidity may result in excess fine sediment accumulation within salamander habitat, which has a negative relationship with relative abundance (Bendik and Dries

214 2018). We therefore expected turbidity to have a negative relationship with survival and the probability of remaining above ground.

216 We summarized mean daily water quality and water quantity statistics for Barton Springs from United 217 States Geological Survey (USGS) gage number 08155500. Mean spring flow, temperature, DO and 218 turbidity were calculated from the mean daily statistics between each period (Table 1). Change in flow 219 was calculated using the difference between the first and last day of the interval between surveys (Table 220 1). All covariates were z-scored prior to analysis. Rather than include all possible combinations of covariate parameterizations in our model set, we chose the three sets of covariates to evaluate as a 222 function of survival and/or temporary emigration: "flow-only" (mean flow + change in flow), "flow223 temp-turbidity" (mean flow + change in flow + mean temp + mean turbidity), and "turb-DO" (turbidity + 224 DO). Because water temperature and flow can be correlated with DO, we excluded those combinations 225 (e.g., flow and DO: $\rho=0.74, P=0.003$ ). We did not find problems with multicollinearity among covariates based on a condition number test. We tested all combinations of the specified covariate and 227 non-covariate models for survival and temporary emigration for a resulting model set of $n=80$. 
228 We also included individual covariates of body size on survival and temporary emigration. We expected 229 survival to be lower for juvenile salamanders compared to adults (Lee et al. 2012, Messerman et al. 230 2020). Furthermore, lower swimming performance in smaller salamanders (e.g., in Eurycea bislineata; 231 Azizi and Landberg 2002) may inhibit them from migrating back through flowing spring orifices, thus

232 limiting their potential for temporary emigration away from the study site. Because size cannot be 233 observed when individuals are not captured, we used a von Bertalanffy growth model (Eaton and Link 234 2011) to predict body lengths for unobserved individuals following first capture. Several parameters are 235 required to describe a von Bertalanffy growth function: initial size ( $s[0])$, asymptotic size ( $a)$, and a 236 growth rate coefficient $(k)$. An additional parameter, $\lambda$, represents individual heterogeneity in the growth 237 curves as the mean to variance ratio (Eaton \& Link, 2011). Using Bayesian analysis in JAGS (Plummer 238 2003), we estimated parameters $a, k, \lambda$ as well as standard deviation of measurement error (sdme) from 239 body size measurements of up to five between-period recaptures, including individuals below our size 240 cutoff. Thus, we took advantage of all the recapture information from smaller individuals to estimate the 241 growth curve, even though some of these were excluded from the CMR analysis. Four chains of 100,000 242 iterations were run following a burn-in of 30,000, and convergence was confirmed via examination of 243 trace plots and Gelman and Rubin's (1992) diagnostic. We used the posterior means of $a$ and $k$, and the 244 initial size, $s[0]=7.53 \mathrm{~mm}$ (based on observations of captured hatchlings) to predict sizes. Size covariates 245 were coded as categorical variables based on the mean size at first capture among recaptured individuals 246 (24.2 $\mathrm{mm})$. This allowed for an even distribution among recaptures that would transition to a larger size.

247 Individuals $>24.2 \mathrm{~mm}$ were coded as 1 , all others as 0 , and transitions from size 1 to size 0 were not 248 permitted. We compared all combinations of models for survival and temporary emigration parameters 249 with body size as a single covariate or as additive with time $(n=26)$.

250 Our approach assumes transitions between states are estimated without error and we did not attempt to 251 incorporate uncertainty in predictions of size. Although transition rates between states can be estimated 252 with multi-state capture-recapture models (Lebreton et al. 2009), we view the growth model approach as 253 more accurate because it directly incorporates information (initial size, elapsed time between surveys, 254 shape of the growth curve) about the transition (growth) process. To assess the sensitivity of this approach 255 to variation in the growth rate parameters, we performed a bootstrapping procedure with 1000 iterations. 256 For each iteration, we randomly sampled parameter estimates of $a$ and $k$ from a single posterior MCMC 257 draw. Next, we estimated size classes for all individuals after first capture, if unobserved. We then 258 performed model fitting for the top model with size as a covariate on $S, \gamma$ ”, and/or $\gamma^{\prime}$. Finally, we 259 calculated Akaike Information Criterion corrected for small samples (AICc) to select the best models 260 (Burnham and Anderson 2002a). 
261 We fit the data using maximum likelihood under the Huggins formulation (Huggins 1989, 1991), as

262 implemented in program MARK v 9.0 (White 2020) and used AICc and AICc weights ( $w$ ) to compare the 263 relative strength of each model (Burnham and Anderson 2002a). We used the package RMark v 2.2.7

264 (Laake 2013) implemented in R v3.6 and v4.0 (R Core Team 2020) to build models and generate model-

265 averaged parameter estimates. Standard errors for the average of time-varying parameters were calculated 266 using the delta method.

\section{Results}

268 Our capture-recapture data set included 2,046 observations of 1,578 Barton Springs salamanders, 333 of

269 which were recaptured at least once between periods. Almost all salamander observations occurred within

270 the spring pool (99\%) and only 1\% occurred within the newly constructed stream (the stream was not

271 fully colonized yet; unpublished data). During the first stage of model fitting, the best model of detection

272 was $p=c$ with full-time variation across all survey events $(w=1.00)$. Model-averaged values of $\hat{p}$ ranged

273 from $0.25(\mathrm{SE}=0.054)$ during the second survey of November 2019 to $0.82(\mathrm{SE}=0.043)$ during the first

274 survey of November 2017. The most general models with temporary emigration were ranked higher than

275 the non-movement model $(\triangle \mathrm{AICc}=1065)$, with Markovian movement favored over the random

276 movement model $(w=1.00 ; \Delta \mathrm{AICc}=42.4)$. None of the models including environmental covariates were

277 favored (Table 2; sum of $w=0$ ). In fact, our results indicated the effects of environmental variables (DO,

278 spring flow, turbidity) were far outweighed by the effect of body size as a determinant of surface

279 availability and survival (Table 2). Models with time-varying survival and emigration parameters were

280 also more parsimonious than those where temporal variation was explained by environmental covariates

281 (Table 2). The best model overall was $S$ ( $\sim$ size $), \gamma^{\prime \prime}(\sim$ time + size $), \gamma^{\prime}(\sim$ time $), p=c$ ( period:time) $(w=$

2820.35 ; Table 2). Goodness-of-fit tests are not available for robust-design models, but we note that the order

283 of the top models was invariant to adjustments of the variance inflation factor, $\hat{c}$.

284 Despite models with environmental covariates not ranking highly, a comparison among models $(n=27)$

285 that only included environmental covariates as a function of survival and emigration parameters provides

286 some insight as to the direction of different environmental effects (Table 3). An exhaustive model set of

287 all possible covariate combinations (which is generally not recommended; Burnham and Anderson

288 2002b) precludes use of model averaging of the beta estimates. Instead, we provide coefficients (on the

289 logit scale) from the top five models ( $\operatorname{sum}$ of $\mathrm{AICc} w=0.93$ ) within this subset to illustrate the direction

290 of environmental effects (Table 4). Estimates for the top models were generally consistent and did not

291 change sign (Table 4). Flow-temp-turbidity and flow-only models of survival outperformed turb-DO

292 models, while turb-DO models for emigration were favored over others (Table 3). Temperature and flow

293 were positively correlated with survival, which was consistent with our hypothesis (Table 4). Turbidity

Peer] reviewing PDF | (2020:12:55968:1:0:NEW 25 Feb 2021) 
294 was positively associated with both emigration parameters, but only significantly so for $\gamma$ ”. DO was 295 negatively associated with both emigration parameters, but again, this affect was negligible for $\gamma^{\prime}$. The 296 remaining coefficients had 95\% confidence intervals overlapping zero (Table 4). Collectively, these 297 results suggest that salamanders move below ground with increasing turbidity and decreasing DO, which 298 was consistent with our expectation.

299 Growth was modeled from 901 measurements of 372 recaptured individuals. Mean parameter estimates 300 with 95\% credence intervals from the von Bertalanffy growth model were as follows: $a=31.57$ (30.99$30132.18), k=7.81$ (7.14-8.52), $\lambda=4.49$ (3.34-6.01) and $s d m e=1.25$ (1.11-1.39). The bootstrap analysis 302 using random draws from the posterior distributions of parameter estimates from the growth model 303 showed little variation in AICc for the top model (range 10654.32-10655.75), indicating that different 304 potential realizations of the individual growth trajectories (based on the population mean) have little 305 impact on our inference. This is due to our study design sampling intervals being long enough and growth 306 of salamanders fast enough (Figure 3), that small shifts in growth rate parameters have a negligible effect 307 on the predicted transition rates between size classes at the resolution of our data.

308 Body size had a positive effect on $S$ and $\gamma$ ”. Estimates of the body size effect on the logit scale (beta) 309 from the top model were $1.43(\mathrm{SE}=0.17)$ and $1.45(\mathrm{SE}=0.28)$ for $S$ and $\gamma$ ”, respectively. Among both 310 size classes, estimates of monthly apparent survival, $\hat{S}$, ranged between $0.75(\mathrm{SE}=0.04)$ and $0.95(\mathrm{SE}=$ 3110.02 ) (Figure 4A), which corresponds to annual survival rates between 0.03 and 0.52 . Temporary 312 emigration varied among size classes ( $\gamma^{\prime \prime}$ range: $\left.0.16-0.97\right)$; the probability of moving from the pool to 313 subterranean habitat was higher for larger individuals (mean $\gamma^{\prime \prime}=0.79, \mathrm{SE}=0.02$ ) compared to smaller 314 individuals (mean $\widehat{\gamma}^{\prime \prime}=0.53, \mathrm{SE}=0.06$ ) (Figure 4). Similarly, the probability of remaining in 315 subterranean habitat $\left(\hat{\gamma}^{\prime}\right.$ range: 0.59-0.96) was higher for larger individuals (mean $\hat{\gamma}^{\prime}=0.86, \mathrm{SE}=0.02$ ) 316 than smaller individuals (mean $\hat{\gamma}^{\prime}=0.77, \mathrm{SE}=0.17$ ) (Figure 4). Abundance $(\hat{N})$ at the surface during each 317 primary period ranged from $62(\mathrm{SE}=3)$ to $377(\mathrm{SE}=9)$ (Figure 5).

318 A typical recaptured individual was not observed for at least one survey period before being observed 319 again, which is consistent with the high estimates of temporary emigration. The median time for between320 period recaptures was 105 days, which is the average time interval between surveys. In some cases, 321 individuals were not observed for several survey periods before being recaptured. For example, $20 \%$ of 322 between-period recaptures (66 of 333) were not seen for more than one year at some point during the 323 study, and 13 individuals had at least a two-year span between observations.

\section{Discussion}

325 Our results contradict characterizations of Barton Springs salamanders as primarily surface-dwellers, or 
326

327

328

329

330

331

332

333

334

335

336

337

338

339

340

341

342

343

344

345

346

347

348

349

350

351

352

353

354

355

356

357

358

as subterranean inhabitants accidentally flushed to the surface (see, e.g., Sweet 1978, Chippindale et al. 1993). Barton Springs salamanders at Eliza Spring can be found in abundance at the surface (Bendik and Dries 2018, Dries and Colucci 2018), but often move underground. High estimates of $\gamma$ ” demonstrate that temporary emigration of individuals from the surface to the subsurface is frequent. A large proportion of individuals also remained underground between surveys, as shown by similarly high estimates of $\gamma^{\prime}$.

Some individuals were not recaptured until more than a year later, suggesting that salamanders may spend long periods of time below ground before returning to the surface. Movements between the surface and subsurface may be a large component of previously observed surface population dynamics, which are characterized by high variability in abundance (Bendik and Dries 2018, Dries and Colucci 2018).

High temporary emigration in Barton Springs salamanders is consistent with observations of other plethodontid salamander populations (Bailey et al. 2004a, 2004b, Price et al. 2012, O'Donnell and Semlitsch 2015, Bendik 2017, Drukker et al. 2018). In general, surface activity of plethodontid salamanders tends to be low, with surface abundance being a small fraction of the superpopulation size (e.g., see Table 1 in O'Donnell and Semlitsch 2015). Plethodontids migrate beneath the forest floor (Bailey et al. 2004a, O'Donnell et al. 2014) or to aquatic subterranean refugia (Bonett and Chippindale 2006, Bendik and Gluesenkamp 2013, Steffen et al. 2014) in response to moisture conditions at the surface, which can influence apparent demographic patterns (Connette et al. 2015, O'Donnell and Semlitsch 2015). Although temporary emigration in plethodontids is common, reasons for lower surface availability of Barton Springs salamanders are likely different than those terrestrial salamanders. Lungless salamanders must keep their skin moist for cutaneous respiration and to prevent water loss (Feder 1983) which influences their surface activity. Neotenic Eurycea require suitable levels of DO (Woods et al. 2010) and flowing water to maintain activity at the surface (Bendik and Gluesenkamp 2013), but otherwise should be unaffected by the challenges of variable moisture faced by their terrestrial counterparts.

Models with environmental effects performed poorly compared to models with individual effects (body size) or time-varying parameters. Despite this, environmental effects can still provide some insight into the temporal variation we observed in salamander movement. Turbidity was positively associated with movement below ground, suggesting that either conditions worsen on the surface during higher turbidity or they improve below ground relative to the surface (e.g., via increased organic matter availability in the subterranean ecosystem). This pattern is consistent with observations of lower surface abundance when fine sediment deposition is high (Bendik and Dries 2018). DO values were negatively associated with salamanders moving below ground but not significantly associated with movement to the surface.

Salamanders may move in response to declining DO in anticipation of adverse conditions, for example, as 
values below $4.4 \mathrm{mg} / \mathrm{L}$ start to have negative effects on salamander growth and survival (Woods et al. 2010). However, this is speculative because DO remained above $4.8 \mathrm{mg} / \mathrm{L}$ during our study (Table 1). Furthermore, DO does not vary substantially between the near-surface and surface habitats and is higher at the springs than deep underground (Mahler and Bourgeais 2013), so salamander movement below ground in search of higher DO conditions is unlikely. However, subterranean habitat could be less metabolically taxing for individuals (e.g., less movement and lower stress due to lack of predation) and prompt migration underground as DO declines. DO is correlated with flow, which was positively associated with survival and consistent with our hypothesis. Other studies have indicated the importance of this variable for Barton Springs salamander population demographics. For example, lagged flow is positively correlated with reproduction and low flows are associated with low abundance (Bendik and Dries 2018; Dries and Colucci 2018). Spring flow may also be associated with food availability within the aquifer, although this hypothesis is untested. Temperatures during our study were within the range for optimal growth for Barton Springs salamanders $\left(15-24^{\circ} \mathrm{C}\right.$; Crow et al. 2016), so response to temperature may be an indicator for other ecological conditions that improve survival, such as food availability, rather than indicating a direct effect on mortality. DO, temperature and flow are intertwined in this system and can exhibit correlated, but complex non-linear relationships (Mahler and Bourgeais 2013), and ultimately it is hard to isolate these effects. While an exhaustive post-hoc analysis of environmental covariates was beyond the scope of this study, this approach might be useful in the future to explore a suite of more complex models.

Smaller salamanders $(<24 \mathrm{~mm}$ body length) had lower survival and a lower probability of moving underground, which was consistent with our prediction. Juvenile Eurycea have difficulty swimming against strong currents (Barrett et al. 2010) and are weaker swimmers than larger individuals (Azizi and Landberg 2002). The spring outlets at Eliza Spring can reach high velocities (mean $=0.16 \mathrm{~m} / \mathrm{s}, \mathrm{SD}=$ 0.16 , $\max =0.65$; City of Austin 2020) in a range that has been shown to flush juvenile Eurycea cirrigera from substrates without gravel (Barrett et al. 2010). If smaller salamanders have more difficulty seeking subterranean refuge at the spring surface, they will be less able to respond to increases in competition for space or predation pressure compared to larger individuals, which more readily move into subterranean refugia. This may, in part, explain why survival is also lower for juvenile salamanders, and could result in a pattern of negative density dependence, as observed in a time-series analysis from two-decades of monthly Barton Springs salamander counts (Bendik and Dries 2018). If this were the case, we should expect survival to vary with both size and year, given the differences in abundance we observed over the course of our study. In our analysis, however, time-dependent models of survival carried less weight (sum of $w=0.44$ ) than those with size alone (sum of $w=0.66$ ). Furthermore, a post-hoc comparison of $S$ with an interaction between year and size did not improve upon our top model, suggesting that if there is a 
393

394

395

396

397

398

399

400

401

402

403

404

405

406

407

408

409

410

411

412

413

414

415

416

417

418

419

420

421

422

survival-density relationship on smaller salamanders, it is not apparent from these data. Negative densitydependence at the surface may also manifest itself through patterns of movement. There is a positive correlation between estimates of $\hat{N}$ at the beginning of the time interval and $\gamma^{\prime \prime}$ for that interval, and this relationship is stronger for the smaller size class (Pearson's product-moment correlation, $\rho=0.60, P=$ $0.02)$ compared to the larger size class $(\rho=0.49, P=0.08)$. Therefore, salamanders may be moving underground in response to increased density at the surface, and there is evidence of density-dependent movement between habitats in other amphibians (Greyson et al. 2011). Alternative statistical approaches to explore the relationship between density and demographic rates may be a useful avenue of future research (e.g., Kissel et al. 2020).

Barton Springs salamanders may move into subterranean refugia for reproduction, or to avoid predation. Egg-laying occurs below ground and courtship may as well, and reproduction is not strictly seasonal as is the case for many other amphibians. Most individuals in the small size class were reproductively immature ( $85 \%$ were $<22.5 \mathrm{~mm}$ in body length; Chippindale et al. 1993), which may partly explain why temporary emigration was lower for this group. Both predators and prey of Barton Springs salamanders are more abundant in surface habitat, but we did not measure variation in either of these factors for this study. Potential predators include crayfish (Procambarus clarkii), mosquitofish (Gambusia affinis) and larval damselflies (e.g., Argia spp.), while their prey includes a variety of invertebrates (DeSantis et al. 2013, Gillespie 2013, Owen et al. 2016, Davis et al. 2017). Below ground, the picture is quite different, where Barton Springs salamanders are likely the top predator (along with the sympatric E. waterlooensis), but invertebrate density is expected be much lower owing to a dearth of primary production in groundwater ecosystems (Gibert et al. 1994). Barton Springs salamanders may therefore face a tradeoff between increased food availability at the surface vs. little to no interspecific predation in subterranean habitat. Growth is size-dependent and occurs rapidly during the first year of life (Figure 3), so salamanders may take advantage of the resource-rich environment at the surface and therefore spend more time above ground when young. However, more research is required to understand ecological consequences of surface and subterranean habitat for these salamanders. Unfortunately, the subterranean ecology of the Barton Springs segment of the Edwards Aquifer is largely undocumented; even basic research on the diversity and distribution of its fauna is scarce (but see Hutchins 2018, Nissen et al. 2018), despite otherwise extensive study of its hydrogeology and geochemistry (Hunt et al. 2019 and references therein). 


\section{Conservation Implications}

424 The City of Austin has a Habitat Conservation Plan that includes numerous measures to improve the 425 surface habitat for Barton Springs salamanders, such as sediment mitigation and habitat expansion (Dries 426 et al. 2013). Given the limited extent to which conservation actions can be implemented at Barton 427 Springs, we believe improvement of surface habitat continues to be a worthwhile goal. The high 428 frequency of movement between the surface and subsurface indicates that the population at Eliza Spring 429 is not a population sink maintained solely by immigration from the aquifer, and that a large proportion of 430 the population associated with the surface is typically underground. Thus, conservation actions meant to 431 improve population persistence at the surface therefore have the potential to improve persistence of the 432 local resident population in and around Barton Springs. For example, a recent expansion of surface 433 habitat at Eliza Spring occurred with the addition of an overland stream (Figure 2B). Moving forward, we 434 can build on results from this study to examine if carrying capacity or survival improve because of the 435 newly expanded habitat. Furthermore, periodic declines in apparent surface abundance do not necessarily 436 reflect an existential threat to the species, as was once thought. However, the extent to which local 437 population persistence contributes to the conservation status of the species as a whole is uncertain. Newly 438 documented localities for Barton Springs salamanders (Devitt and Nissen 2018) expand the known range 439 of this species by (potentially) hundreds of square km within the Barton Springs segment of the Edwards 440 Aquifer and the adjacent Trinity Aquifer. One individual was captured deep within a well (McDermid et 441 al. 2015), while others have been regularly observed within a cave stream that eventually flows to Barton 442 Springs (Blowing Sink Cave; Bendik et al. 2013a; City of Austin 2018a). Data on abundance and density

443 for populations outside of Barton Springs are scarce and difficult to obtain, but available evidence 444 suggests that both population density and spatial density (number of sites/area) both appear to be lower 445 outside of the Barton Springs complex (Devitt and Nissen 2018, Dries and Colucci 2018; City of Austin 446 2018a). While this observation is partly biased by our inability to adequately explore subterranean 447 habitats, it underscores the need to understand how populations at the endpoint of the Barton Springs 448 system interact with other, lower density populations throughout their range. The direction and frequency 449 of gene flow throughout the range of Barton Springs salamanders is of particular interest, because species 450 persistence may hinge on the interconnectivity of these sparse populations (City of Austin 2018b).

451 However, because of limited access to subterranean sites, inferences about population connectivity may 452 have to rely on fortuitous sampling of difficult-to-access habitat.

\section{Conclusions}

454 Since they were described from a single spring locality in 1993, knowledge of Barton Springs salamander 455 population ecology has mostly been gleaned from surface count surveys, limiting any inference about 
456 what we now know is a fraction of a larger superpopulation (City of Austin 1997, U.S. Fish and Wildlife

457 Service 2016, Bendik and Dries 2018, Dries and Colucci 2018). Using an indirect approach to detect

458 movement, we quantified temporary emigration of Barton Springs salamanders into subterranean habitat

459 from capture-recapture data. Temporary emigration was frequent, indicating that apparent abundance at

460 the surface is not solely a function of immigration, recruitment and/or survival. Furthermore, these

461 findings suggest that periodic declines in surface abundance of Barton Springs salamanders at Barton

462 Springs are not wholly caused by mortalities, but may include emigration to adjacent, unobservable

463 habitat. Our results demonstrate the utility of using estimates of temporary emigration to understand

464 movement and habitat use in species where direct observation may not always be possible.

\section{Acknowledgements}

466 We thank the following individuals for aiding with field surveys (in no particular order): Justin Crow, 467 Pete Diaz, Andy Gluesenkamp, Romey Swanson, Kelsey Anderson, Radmon Rice, Donella Strom, Saj 468 Zappitello, Crystal Datri, Lindsey Sydow, Scott Hiers, Jonny Scalise, Charlotte Kucera, Todd Jackson, 469 Luis Medina, Liza Colucci, and Jesse Meik. Jesse Meik and two anonymous reviewers provided helpful 470 comments on the manuscript. The findings and conclusions in this article are those of the author(s) and do 471 not necessarily represent the views of the U.S. Fish and Wildlife Service.

472

\section{References}

474 Azizi, E., and T. Landberg. 2002. Effects of metamorphosis on the aquatic escape response of 475 the two-lined salamander (Eurycea bislineata). The Journal of Experimental Biology $476 \quad 205: 841-849$.

477 Bailey, L. L., and E. Muths. 2019. Integrating amphibian movement studies across scales better 478 informs conservation decisions. Biological Conservation 236:261-268.

479 Bailey, L. L., T. R. Simons, and K. H. Pollock. 2004a. Spatial and temporal variation in 480 detection probability of Plethodon salamanders using the robust capture-recapture design. 481 Journal of Wildlife Management 68:80-90.

482 Bailey, L. L., T. R. Simons, and K. H. Pollock. 2004b. Estimating detection probability 483 parameters for Plethodon salamanders using the robust capture-recapture design. Journal of 484 Wildlife Management 68:67-79.

485 Balázs, G., B. Lewarne, and G. Herczeg. 2020. Extreme site fidelity of the olm (Proteus 486 anguinus) revealed by a long-term capture-mark-recapture study. Journal of Zoology 
487

488

489

490

491

492

493

494

495

496

497

498

499

500

501

502

503

504

505

506

507

508

509

510

511

512

513

514

515

516

517

311:99-105.

Băncilă, R. I., R. Pradel, R. Choquet, R. Plăiaşu, and O. Gimenez. 2018. Using temporary emigration to inform movement behaviour of cave-dwelling invertebrates: a case study of a cave harvestman species. Ecological Entomology 43:551-559.

Barrett, K., B. S. Helms, C. Guyer, and J. E. Schoonover. 2010. Linking process to pattern: causes of stream-breeding amphibian decline in urbanized watersheds. Biological Conservation 143:1998-2005.

Bendik, N. F. 2017. Demographics, reproduction, growth, and abundance of Jollyville Plateau salamanders (Eurycea tonkawae). Ecology and Evolution 7:5002-5015.

Bendik, N. F., and L. A. Dries. 2018. Density-dependent and density-independent drivers of population change in Barton Springs salamanders. Ecology and Evolution 8:5912-5923.

Bendik, N. F., and A. G. Gluesenkamp. 2013. Body length shrinkage in an endangered amphibian is associated with drought. Journal of Zoology 290:35-41.

Bendik, N. F., J. M. Meik, A. G. Gluesenkamp, C. E. Roelke, and P. T. Chippindale. 2013a. Biogeography, phylogeny, and morphological evolution of central Texas cave and spring salamanders. BMC Evolutionary Biology 13:201.

Bendik, N. F., T. A. Morrison, A. G. Gluesenkamp, M. S. Sanders, and L. J. O’Donnell. 2013 b. Computer-assisted photo identification outperforms visible implant elastomers in an endangered salamander, Eurycea tonkawae. PloS one 8:e59424.

Bolger, D. T., T. A. Morrison, B. Vance, D. Lee, and H. Farid. 2012. A computer-assisted system for photographic mark-recapture analysis. Methods in Ecology and Evolution $3: 813-822$.

Bonett, R. M., and P. T. Chippindale. 2006. Streambed microstructure predicts evolution of development and life history mode in the plethodontid salamander Eurycea tynerensis. BMC biology 4:6.

Bowles, D. E., and T. L. Arsuffi. 1993. Karst aquatic ecosystems of the Edwards Plateau region of central Texas: a consideration of their importance, threats to their existance and efforts for their conservation. Aquatic Conservation: Marine and Freshwater Ecosystems 3:317329.

Burnham, K. P., and D. R. Anderson. 2002a. Model selection and multi-model inference: a practical information-theoretic approach. 2nd edition. New York: Springer. 
518 Burnham, K. P., and D. R. Anderson. 2002b. Avoiding pitfalls when using information-theoretic 519 methods. The Journal of Wildlife Management 66:912-918.

520 Catenazzi, A. 2015. State of the world's amphibians. Annual Review of Environment and $521 \quad$ Resources 40:91-119.

522 Cayuela, H., A. Valenzuela-Sánchez, L. Teulier, Í. Martínez-Solano, J. P. Léna, J. Merilä, E. 523 Muths, R. Shine, L. Quay, M. Denoël, J. Clobert, and B. R. Schmidt. 2020. Determinants 524 and consequences of dispersal in vertebrates with complex life cycles: A review of pond525 breeding amphibians. Quarterly Review of Biology 95:1-36.

526 Cecala, K. K., S. J. Price, and M. E. Dorcas. 2013. Modeling the effects of life-history traits on 527 estimation of population parameters for a cryptic stream species. Freshwater Science $528 \quad 32: 116-125$.

529 Chippindale, P. T., and A. H. Price. 2005. Conservation of Texas spring and cave salamanders 530 (Eurycea). In: M. Lannoo, ed. Amphibian Declines: The Conservation Status of United 531 States Species. Berkeley: University of California Press, 193-197.

532 Chippindale, P. T., A. H. Price, and D. M. Hillis. 1993. A new species of perennibranchiate 533 salamander (Eurycea: Plethodontidae) from Austin, Texas. Herpetologica 49:248-259.

534 City of Austin. 1997. The Barton Creek Report. CM-97-03. City of Austin, Watershed Protection 535 Department. Austin, TX.

536 http://www.austintexas.gov/watershed_protection/publications/document.cfm?id=186157 $537 \quad$ (accessed 27 October 2020)

538 City of Austin. 2018a. Estimates of abundance of Barton Springs salamanders at Eliza Spring 539 using capture-mark-recapture. DR-18-03. City of Austin, Watershed Protection Department. $540 \quad$ Austin, Texas.

541 http://www.austintexas.gov/watershed protection/publications/document.cfm?id=290630

$542 \quad$ (accessed 27 October 2020)

543 City of Austin. 2018b. 2018 Annual Report, U.S. Fish and Wildlife Service Scientific Permit TE544 833851. City of Austin, Watershed Protection Department. Austin, Texas.

545

546 City of Austin. 2020. Barton Springs salamander project 26 data. City of Austin open data portal, 547 Austin, TX. https://data.austintexas.gov/Environment/Barton-Springs-Salamander-project$548 \quad \underline{26-d a t a / q x q z-z c z q / d a t a}$ (accessed 27 October 2020) 
549 Connette, G. M., J. A. Crawford, and W. E. Peterman. 2015. Climate change and shrinking 550 salamanders: alternative mechanisms for changes in plethodontid salamander body size. $551 \quad$ Global Change Biology 21:2834-2843.

552 Crow, J., M. Forstner, K. Ostrand, and J. Tomasso. 2016. The role of temperature on survival 553 and growth of the Barton Springs Salamander (Eurycea sosorum). Herpetological $554 \quad$ Conservation and Biology 11:328-334.

555 Culver, D. C., L. L. Master, M. C. Christman, and H. H. Hobbs III. 2000. Obligate cave fauna of 556 557 558

559

560

561

562

563

564

565

566

567

568

569

570

571

572

573

574

575

576

577

578

579 the 48 contiguous United States. Conservation Biology 14:386-401.

Davis, D. R., D. L. DeSantis, and C. R. Gabor. 2017. Antipredator behavior of the Barton Springs salamander (Eurycea sosorum) in response to aquatic invertebrates: potential consequences of habitat restoration. Hydrobiologia 795:129-137.

Day, J., J. E. Gerken, and G. L. Adams. 2016. Population ecology and seasonal demography of the endangered grotto sculpin (Cottus specus). Ecology of Freshwater Fish 25:27-37.

DeSantis, D. L., D. R. Davis, and C. R. Gabor. 2013. Chemically mediated predator avoidance in the Barton Springs Salamander (Eurycea sosorum). Herpetologica 69:291-297.

Devitt, T. J., and B. D. Nissen. 2018. New occurrence records for Eurycea sosorum Chippindale, Price \& Hillis, 1993 (Caudata, Plethodontidae) in Travis and Hays counties, Texas, USA. Check List 14:297-301.

Devitt, T. J., A. M. Wright, D. C. Cannatella, and D. M. Hillis. 2019. Species delimitation in endangered groundwater salamanders: implications for aquifer management and biodiversity conservation. Proc Natl Acad Sci U S A 116:2624-2633..

DiStefano, R. J., D. Ashley, S. K. Brewer, J. B. Mouser, and M. Niemiller. 2020. Preliminary investigation of the critically imperiled Caney Mountain cave crayfish Orconectes stygocaneyi (Hobbs III, 2001) (Decapoda: Cambaridae) in Missouri, USA. Freshwater Crayfish 25:47-57.

Dries, L. A., and L. A. Colucci. 2018. Variation in abundance in the Barton Springs salamander associated with flow regime and drought. Herpetological Conservation and Biology 13:302-316.

Dries, L. A., C. Herrington, L. A. Colucci, N. F. Bendik, D. A. Chamberlain, D. A. Johns, and E. Peacock. 2013. Major amendment and extension of the habitat conservation plan for the Barton Springs Salamander (Eurycea sosorum) and the Austin Blind Salamander (Eurycea 
580

581

582

583

584

585

586

587

588

589

590

591

592

593

594

595

596

597

598

599

600

601

602

603

604

605

606

607

608

609

610

waterlooensis) to allow for the operation and maintenance of Barton Springs and adjacent springs. City of Austin, Austin, TX.

http://www.austintexas.gov/watershed_protection/publications/document.cfm?id=196468 (accessed 27 October 2020)

Drukker, S. S., K. K. Cecala, P. R. Gould, B. A. McKenzie, and C. Van De Ven. 2018. The ecology and natural history of the cumberland dusky salamander (Desmognathus abditus): distribution and demographics. Herpetological Conservation and Biology 13:33-46.

Eaton, M. J., and W. A. Link. 2011. Estimating age from recapture data: integrating incremental growth measures with ancillary data to infer age-at-length. Ecological Applications 21:2487-2497.

Feder, M. E. 1983. Integrating the ecology and physiology of plethodontid salamanders. Herpetologica 39:291-310.

Fenolio, D. B., M. L. Niemiller, M. G. Levy, and B. Martinez. 2013. Conservation status of the Georgia Blind Salamander (Eurycea wallacei) from the Floridan Aquifer of Florida and Georgia. IRCF Reptiles \& Amphibians 20:97-111.

Fries, J. N. 2002. Upwelling flow velocity preferences of captive adult San Marcos salamanders. North American Journal of Aquaculture 64:113-116.

Gelman, A., and D. B. Rubin. 1992. Inference from iterative simulation using multiple sequences. Statistical Science 7:457-472.

Gibert, J., D. L. Danielopol, and J. A. Stanford. 1994. Groundwater Ecology. San Diego: Academic Press.

Gillespie, J. H. 2013. Application of stable isotope analysis to study temporal changes in foraging ecology in a highly endangered amphibian. PLoS ONE 8:e53041.

Gorički, Š., M. L. Niemiller, D. B. Fenolio, and A. G. Gluesenkamp. 2019. Salamanders. In: W. B. White, D. C. Culver, and T. Pipan, ed. Encyclopedia of Caves. 3rd Edition. Academic Press, 871-884.

Graening, G. O., D. B. Fenolio, M. L. Niemiller, A. V. Brown, and J. B. Beard. 2010. The 30year recovery effort for the Ozark cavefish (Amblyopsis rosae): Analysis of current distribution, population trends, and conservation status of this threatened species. Environmental Biology of Fishes 87:55-88.

Grant, E. H. C., D. A. W. Miller, B. R. Schmidt, M. J. Adams, S. M. Amburgey, T. Chambert, S. 
611

612

613

614

615

616

617

618

619

620

621

622

623

624

625

626

627

628

629

630

631

632

633

634

635

636

637

638

639

640

641

S. Cruickshank, R. N. Fisher, D. M. Green, B. R. Hossack, P. T. J. Johnson, M. B. Joseph, T. A. G. Rittenhouse, M. E. Ryan, J. H. Waddle, S. C. Walls, L. L. Bailey, G. M. Fellers, T. A. Gorman, A. M. Ray, D. S. Pilliod, S. J. Price, D. Saenz, W. Sadinski, and E. Muths. 2016. Quantitative evidence for the effects of multiple drivers on continental-scale amphibian declines. Scientific Reports 6:25625.

Grayson, K. L., L. L. Bailey, and H. M. Wilbur. 2011. Life history benefits of residency in a partially migrating pond-breeding amphibian. Ecology 92:1236-1246.

Huggins, R. M. 1989. On the statistical analysis of capture experiments. Biometrika 76:133-140.

Huggins, R. M. 1991. Some practical aspects of a conditional likelihood approach to capture experiments. Biometrics 47:725.

Hunt, B. B., B. A. Smith, and N. M. Hauwert. 2019. Barton Springs segment of the Edwards (Balcones Fault Zone) Aquifer, central Texas. In: J. M. J. Sharp, R. T. Green, and G. M. Schindel, ed. The Edwards Aquifer: The Past, Present, and Future of a Vital Water Resource. Geological Society of America Memoir 215.

Hutchins, B. T. 2018. The conservation status of Texas groundwater invertebrates. Biodiversity and Conservation 27:475-501.

Jugovic, J., E. Praprotnik, E. V. Buzan, and M. Lužnik. 2015. Estimating population size of the cave shrimp Troglocaris anophthalmus (Crustacea, Decapoda, Caridea) using markrelease-recapture data. Animal Biodiversity and Conservation 38:77-86.

Kendall, W. L., and R. Bjorkland. 2001. Using open robust design models to estimate temporary emigration from capture-recapture data. Biometrics 57:1113-1122.

Kendall, W., J. Nichols, and J. Hines. 1997. Estimating temporary emigration using capturerecapture data with Pollock's robust design. Ecology 78:563-578.

Kissel, A. M., S. Tenan, and E. Muths. 2020. Density dependence and adult survival drive dynamics in two high elevation amphibian populations. Diversity 12:1-15.

Krejca, J. K., and B. Weckerly. 2007. Detection probabilities of karst invertebrates. Pages 283289 National Cave and Karst Management Symposium.

Krejca J. K. and J. Reddell. Biology and ecology of the Edwards Aquifer. In: J. M. J. Sharp, R. T. Green, and G. M. Schindel, ed. The Edwards Aquifer: The Past, Present, and Future of a Vital Water Resource. Geological Society of America Memoir 215. 159-169.

Laake, J. L. 2013. RMark: An R interface for analysis of capture-recapture data with MARK. 
642

643

644

645

646

647

648

649

650

651

652

653

654

655

656

657

658

659

660

661

662

663

664

665

666

667

668

669

670

671

672

AFSC Processed Rep. 2013-01, 25 p. Alaska Fish. Sci. Cent.,NOAA, Natl. Mar. Fish. Serv., 7600 Sand Point Way NE, Seattle WA 98115.

Lannoo, M. 2005. Amphibian Declines: The Conservation Status of United States Species. University of California Press, Berkeley and Los Angeles.

Lebreton, J. D., K. P. Burnham, J. Clobert, and D. R. Anderson. 1992. Modeling survival and testing biological hypotheses using marked animals: a unified approach with case studies. Ecological Monographs 62:67-118.

Lebreton, J. D., J. D. Nichols, R. J. Barker, R. Pradel, and J. A. Spendelow. 2009. Modeling Individual Animal Histories with Multistate Capture-Recapture Models. Advances in Ecological Research. First edition. Elsevier Ltd. pp 87-173.

Lee, D. E., J. B. Bettaso, M. L. Bond, R. W. Bradley, J. R. Tietz, and P. M. Warzybok. 2012. Growth, age at maturity, and age-specific survival of the Arboreal Salamander (Aneides lugubris) on Southeast Farallon Island, California. Journal of Herpetology 46:64-71.

Lopes Ferreira, R., X. Prous, S. Fortes Machado, and R. Parentoni Martins. 2005. Population dynamics of Loxosceles similis (Moenkhaus, 1898) in a brazilian dry cave: a new method for evaluation of population size. Revista Brasileira de Zoociências 7:129-141.

Lowe, W. H., G. E. Likens, and B. J. Cosentino. 2006. Self-organisation in streams: the relationship between movement behaviour and body condition in a headwater salamander. Freshwater Biology 51:2052-2062.

Mahler, B. J., and R. Bourgeais. 2013. Dissolved oxygen fluctuations in karst spring flow and implications for endemic species: Barton Springs, Edwards Aquifer, Texas, USA. Journal of Hydrology 505:291-298.

Mammola, S., Cardoso, P., Culver, D.C., Deharveng, L., Ferreira, R.L., Fišer, C., Galassi, D.M., Griebler, C., Halse, S., Humphreys, W.F. and Isaia, M., 2019. Scientists' warning on the conservation of subterranean ecosystems. BioScience, 69:641-650.

Marsh, D. M., G. S. Milam, N. P. Gorham, and N. G. Beckman. 2005. Forest roads as partial barriers to terrestrial salamander movement. Conservation Biology 19:2004-2008.

McDermid, K., P. Sprouse, and J. Krejca. 2015. Geographic Distribution: Eurycea sosorum (Barton Springs salamander). Herpetological Review 46:556-578.

Means, M. L., and J. E. Johnson. 1995. Movement of threatened Ozark cavefish in Logan Cave National Wildlife Refuge, Arkansas. The Southwestern Naturalist 40:308-313. 
673 Messerman, A. F., R. D. Semlitsch, and M. Leal. 2020. Estimating survival for elusive juvenile 674 pond-breeding salamanders. Journal of Wildlife Management 84:562-575.

675 Miller, B. T., and M. L. Niemiller. 2008. Distribution and relative abundance of Tennessee Cave 676 Salamanders (Gyrinophilus palleucus and Gyrinophilus gulolineatus) with an emphasis on 677 Tennessee populations. Herpetological Conservation and Biology 3:1-20.

678 Nathan, R., W. M. Getz, E. Revilla, M. Holyoak, R. Kadmon, D. Saltz, and P. E. Smouse. 2008. 679 A movement ecology paradigm for unifying organismal movement research. Proc Natl 680 Acad Sci U S A 105:19052-19059.

681 Niemiller, M. L., B. M. Glorioso, D. B. Fenolio, R. G. Reynolds, S. J. Taylor, and B. T. Miller. 682 2016. Growth, survival, longevity, and population size of the Big Mouth Cave Salamander 683 (Gyrinophilus palleucus necturoides) from the type locality in Grundy County, Tennessee, $684 \quad$ USA. Copeia:35-41.

685 Nissen, B. D., T. J. Devitt, N. F. Bendik, A. G. Gluesenkamp, and R. Gibson. 2018. New 686 occurrence records for stygobiontic invertebrates from the Edwards and Trinity aquifers in 687 west-central Texas, USA. Subterranean Biology 28:1-13.

688 O’Donnell, K. M., and R. D. Semlitsch. 2015. Advancing terrestrial salamander population 689 ecology: the central role of imperfect detection. Journal of Herpetology 49:533-540.

690 O’Donnell, K. M., F. R. Thompson, and R. D. Semlitsch. 2014. Predicting variation in 691 microhabitat utilization of terrestrial salamanders. Herpetologica 70:259-265.

692 Owen, J. D., T. J. Devitt, L. A. Colucci, and N. F. Bendik. 2016. Natural History Notes: Eurycea 693 694 695 696 697 698 699 700 701 702 703 sosorum (Barton Springs Salamander). Predation and diet. Herpetological Review 47:275.

Phillips, J. G., D. B. Fenolio, S. L. Emel, and R. M. Bonett. 2017. Hydrologic and geologic history of the Ozark Plateau drive phylogenomic patterns in a cave-obligate salamander. Journal of Biogeography 44:2463-2474.

Pittman, S. E., M. S. Osbourn, and R. D. Semlitsch. 2014. Movement ecology of amphibians: a missing component for understanding population declines. Biological Conservation 169:4453.

Plummer, M. 2003. JAGS: A program for analysis of Bayesian graphical models using Gibbs sampling. Proceedings of the 3rd International Workshop on Distributed Statistical Computing:1-10.

Pollock, K. H. K. 1982. A capture-recapture design robust to unequal probability of capture. The 
$704 \quad$ Journal of Wildlife Management 46:752-757.

705 Price, S. J., R. A. Browne, and M. E. Dorcas. 2012. Resistance and resilience of a stream 706 salamander to supraseasonal drought. Herpetologica 68:312-323.

707 Pulliam, H. R. 1988. Sources, sinks, and population regulation. American Naturalist 132:652$708 \quad 661$.

709 R Core Team (2020). R: A language and environment for statistical computing. R Foundation

710 for Statistical Computing, Vienna, Austria. https://www.R-project.org/. (accessed 27

711 October 2020)

712 Rasband, W. S. 1997. ImageJ. Bethesda, Maryland, USA. https://imagej.nih.gov/ij// (accessed 27

713 October 2020)

714 Ringler, M., E. Ursprung, and W. Hödl. 2009. Site fidelity and patterns of short- and long-term

715 movement in the brilliant-thighed poison frog Allobates femoralis (Aromobatidae).

716 Behavioral Ecology and Sociobiology 63:1281-1293.

717 Steffen, M., K. Irwin, A. Blair, and R. Bonett. 2014. Larval masquerade: a new species of

718 paedomorphic salamander (Caudata: Plethodontidae: Eurycea) from the Ouachita

719 Mountains of North America. Zootaxa 3786:423-442.

720 Sweet, S. S. 1978. The Evolutionary Development of the Texas Eurycea. Unpublished

721 dissertation. University of California, Berkeley.

722 Trajano, E. 1997. Population ecology of Trichomycterus itacarambiensis, a cave catfish from 723 eastern Brazil (Siluriformes, Trichomycteridae). Environmental Biology of Fishes 50:357$724 \quad 369$.

725 Trontelj, P., C. J. Douady, C. Fišer, J. Gibert, Š. Gorički, T. Lefébure, B. Sket, and V. Zakšek. 726 2009. A molecular test for cryptic diversity in ground water: How large are the ranges of 727 macro-stygobionts? Freshwater Biology 54:727-744.

728 U.S. Fish and Wildlife Service. 1997. Final rule to list the Barton Springs salamander as 729 endangered. Federal Register 62:23377-23392.

730 U.S. Fish and Wildlife Service. 2016. Recovery plan for the Barton Springs Salamander, 731 Eurycea sosorum amended to include Austin Blind Salamander (Eurycea 732 waterlooensis):148 pp.

733 https://www.fws.gov/southwest/es/Documents/R2ES/BSS_Recovery_Plan_with_Austin_B1

$734 \quad$ ind Sal Addendum.pdf (accessed 27 October 2020) 
735 Wen, Z., K. Pollock, J. Nichols, and P. Waser. 2011. Augmenting superpopulation capture736 recapture models with population assignment data. Biometrics 67:691-700.

737 White, G. C. 2020. Program MARK. Fort Collins, Colorado.

738 http://www.phidot.org/software/mark/ (accessed 27 October 2020)

739 Woods, H. A., M. F. Poteet, P. D. Hitchings, R. A. Brain, and B. W. Brooks. 2010. Conservation 740 physiology of the plethodontid salamanders Eurycea nana and E. sosorum: response to 741 declining dissolved oxygen. Copeia 2010:540-553.

742 Wynne, J. J., F. G. Howarth, S. Sommer, and B. G. Dickson. 2019. Fifty years of cave arthropod 743 sampling: techniques and best practices. International Journal of Speleology 48:33-48. 744 


\section{Table $\mathbf{1}$ (on next page)}

Summary of environmental variables measured at Barton Springs from USGS site 08155500 .

Means were computed from daily statistics for each sampling interval. The grand mean and pooled range are summary statistics for the sampling interval means (i.e., the covariate values used). The total range represents the range of all daily statistics. 
1 Table 1. Summary of environmental variables measured at Barton Springs from USGS site 208155500.

\begin{tabular}{|l|l|l|l|}
\hline Variable & Grand Mean \pm SD & Pooled Range & Total Range \\
\hline Flow $\left(\mathrm{ft}^{3} / \mathrm{s}\right)$ & $86.3 \pm 26.5$ & $41-123$ & $26-131$ \\
\hline Change in flow $\left(\mathrm{ft}^{3} / \mathrm{s}\right)$ & $4.05 \pm 27.1$ & $-31.3-2.8$ & NA \\
\hline Dissolved oxygen $(\mathrm{mg} / \mathrm{L})$ & $6.06 \pm 0.366$ & $5.38-6.64$ & $4.80-7.50$ \\
\hline Turbidity $(\mathrm{FNU})$ & $2.30 \pm 0.510$ & $1.72-2.52$ & $0.8-31.4$ \\
\hline Temperature $\left({ }^{\circ} \mathrm{C}\right)$ & $21.2 \pm 0.453$ & $20.4-21.9$ & $18.6-22.7$ \\
\hline
\end{tabular}

3 Means were computed from daily statistics for each sampling interval. The grand mean and pooled range

4 are summary statistics for the sampling interval means (i.e., the covariate values used). The total range

5 represents the range of all daily statistics. 


\section{Table 2 (on next page)}

Model selection results based on AICc for the top 15 capture-recapture models of survival, temporary emigration, and capture probability.

$S=$ apparent survival; $\gamma^{\prime \prime}=$ unavailable at the surface $\mid$ present during the last survey; $\gamma^{\prime}=$ unavailable at the surface | unavailable during the last survey. All models shown below include $p=c$ within and between session variation for capture and recapture probabilities. 
1 Table 2. Table of model selection results based on AICc for the top 15 capture-recapture models of 2 survival, temporary emigration, and capture probability.

$3 S=$ apparent survival; $\gamma^{\prime \prime}=$ unavailable at the surface $\mid$ present during the last survey; $\gamma^{\prime}=$ unavailable at

4 the surface $\mid$ unavailable during the last survey. All models shown below include $p=c$ within and

5 between session variation for capture and recapture probabilities.

\begin{tabular}{|c|c|c|c|c|c|}
\hline Model & AICc & $\triangle \mathrm{AICc}$ & $\begin{array}{c}\text { AICc } \\
\text { Weights }(w) \\
\end{array}$ & $\begin{array}{c}\text { Num. } \\
\text { Par }\end{array}$ & -2logLik \\
\hline$S(\sim \operatorname{size}) \gamma^{\prime \prime}(\sim$ time + size $) \gamma^{\prime}(\sim$ time $)$ & 10654.86 & 0.00 & 0.35 & 75 & 10501.47 \\
\hline$S(\sim \operatorname{size}) \gamma^{\prime \prime}(\sim$ time + size $) \gamma^{\prime}(\sim$ time + size $)$ & 10655.12 & 0.26 & 0.31 & 76 & 10499.63 \\
\hline$S(\sim$ year + size $) \gamma^{\prime \prime}(\sim$ time + size $) \gamma^{\prime}(\sim$ time $)$ & 10655.71 & 0.85 & 0.23 & 78 & 10496.04 \\
\hline$S(\sim$ year + size $) \gamma^{\prime \prime}(\sim$ time + size $) \gamma^{\prime}(\sim$ time + size $)$ & 10657.10 & 2.24 & 0.11 & 79 & 10495.33 \\
\hline$S(\sim$ year + size $) \gamma^{\prime \prime}(\sim$ time + size $) \gamma^{\prime}(\sim$ size $)$ & 10680.08 & 25.21 & 0.00 & 67 & 10543.37 \\
\hline$S(\sim$ year + size $) \gamma^{\prime \prime}(\sim$ time $) \gamma^{\prime}(\sim$ time $)$ & 10680.48 & 25.61 & 0.00 & 77 & 10522.90 \\
\hline$S(\sim$ year + size $) \gamma^{\prime \prime}(\sim$ time $) \gamma^{\prime}(\sim$ time + size $)$ & 10682.57 & 27.70 & 0.00 & 78 & 10522.89 \\
\hline$S(\sim$ size $) \gamma^{\prime \prime}(\sim$ time $) \gamma^{\prime}(\sim$ time $)$ & 10685.86 & 31.00 & 0.00 & 74 & 10534.56 \\
\hline$S(\sim$ size $) \gamma^{\prime \prime}(\sim$ time + size $) \gamma^{\prime}(\sim$ size $)$ & 10687.29 & 32.42 & 0.00 & 64 & 10556.82 \\
\hline$S(\sim$ size $) \gamma^{\prime \prime}(\sim$ time $) \gamma^{\prime}(\sim$ time + size $)$ & 10687.85 & 32.98 & 0.00 & 75 & 10534.45 \\
\hline$S(\sim$ year $) \gamma^{\prime \prime}(\sim$ time + size $) \gamma^{\prime}(\sim$ time $)$ & 10692.17 & 37.30 & 0.00 & 77 & 10534.59 \\
\hline$S$ ( flow-temp-turbidity) $\gamma^{\prime \prime}(\sim$ time $) \gamma^{\prime}(\sim$ time $)$ & 10693.31 & 38.44 & 0.00 & 77 & 11715.30 \\
\hline$S(\sim$ year $) \gamma^{\prime \prime}(\sim$ time + size $) \gamma^{\prime}(\sim$ time + size $)$ & 10694.03 & 39.17 & 0.00 & 78 & 10534.35 \\
\hline$S$ ( flow-only) $\gamma^{\prime \prime}$ ( $\sim$ time $) \gamma^{\prime}$ ( time) & 10694.64 & 39.78 & 0.00 & 75 & 11720.82 \\
\hline$S\left(\sim\right.$ turb-DO) $\gamma^{\prime \prime}(\sim$ time $) \gamma^{\prime}(\sim$ time $)$ & 10695.45 & 40.59 & 0.00 & 75 & 11721.63 \\
\hline
\end{tabular}

6 


\section{Table 3 (on next page)}

Model selection results based on AICc for the top subset of models comparing environmental effects on survival and temporary emigration.

$S=$ apparent survival; $\gamma^{\prime \prime}=$ unavailable at the surface $\mid$ present during the last survey; $\gamma^{\prime}=$ unavailable at the surface | unavailable during the last survey. All models shown below include $p=c$ within and between session variation for capture and recapture probabilities. $\Delta \mathrm{AICC}$ values are only relative to this subset of models. 
1 Table 3. Model selection results based on AICc for the top subset of models comparing

2 environmental effects on survival and temporary emigration.

\begin{tabular}{|c|c|c|c|c|c|}
\hline Model & AICc & $\Delta \mathrm{AICc}$ & $\begin{array}{l}\text { AICc } \\
\text { Weights } \\
(w)\end{array}$ & $\begin{array}{l}\text { Num. } \\
\text { Par }\end{array}$ & Deviance \\
\hline$S$ (flow-temp-turbidity) $\gamma^{\prime \prime}$ (turbidity-DO) $\gamma^{\prime}$ (turbidity-DO) & 10749.22 & 0 & 0.38 & 56 & 11814.91 \\
\hline$S$ (flow-only) $\gamma^{\prime \prime}$ (turbidity-DO) $\gamma^{\prime}$ (turbidity-DO) & 10750.43 & 1.21 & 0.21 & 54 & 11820.25 \\
\hline $\begin{array}{l}S \text { (flow-temp-turbidity) } \gamma^{\prime \prime} \text { (turbidity-DO) } \gamma^{\prime} \text { (flow-temp- } \\
\text { turbidity) }\end{array}$ & 10751.59 & 2.36 & 0.12 & 58 & 11813.13 \\
\hline$S$ (flow-only) $\gamma^{\prime \prime}$ (turbidity-DO) $\gamma^{\prime}$ (flow-only) & 10751.92 & 2.69 & 0.10 & 54 & 11821.74 \\
\hline$S$ (flow-temp-turbidity) $\gamma^{\prime \prime}$ (turbidity-DO) $\gamma^{\prime}$ (flow-only) & 10752.11 & 2.89 & 0.09 & 56 & 11817.80 \\
\hline$S$ (flow-only) $\gamma^{\prime \prime}$ (turbidity-DO) $\gamma^{\prime}$ (flow-temp-turbidity) & 10753.53 & 4.31 & 0.04 & 56 & 11819.22 \\
\hline $\begin{array}{l}S \text { (flow-temp-turbidity) } \gamma^{\prime \prime} \text { (flow-temp-turbidity) } \gamma^{\prime} \text { (turbidity- } \\
\text { DO) }\end{array}$ & 10754.79 & 5.57 & 0.02 & 58 & 11816.34 \\
\hline$S$ (flow-only) $\gamma^{\prime \prime}$ (flow-temp-turbidity) $\gamma^{\prime}$ (turbidity-DO) & 10755.53 & 6.30 & 0.02 & 56 & 11821.22 \\
\hline $\begin{array}{l}S \text { (flow-temp-turbidity) } \gamma^{\prime \prime} \text { (flow-temp-turbidity) } \gamma^{\prime} \text { (flow- } \\
\text { temp-turbidity) }\end{array}$ & 10757.31 & 8.09 & 0.01 & 60 & 11814.72 \\
\hline$S$ (flow-only) $\gamma^{\prime \prime}$ (flow-temp-turbidity) $\gamma^{\prime}$ (flow-only) & 10757.37 & 8.15 & 0.01 & 56 & 11823.06 \\
\hline
\end{tabular}




\section{Table 4 (on next page)}

Coefficients representing environmental effects from the subset of models comparing environmental effects on survival and temporary emigration.

Estimates (and 95\% confidence intervals) on the logit-scale are represented in boldface if the confidence interval did not contain zero. Values are given for the top five models within this subset (sum of AlCC $w=0.93$ ). 

temporary emigration.

3 Estimates (and 95\% confidence intervals) on the logit-scale are represented in boldface if the confidence interval did not contain zero.

\begin{tabular}{|c|c|c|c|c|c|}
\hline \multirow[b]{2}{*}{ Parameter, covariate } & \multicolumn{5}{|c|}{ Model sub-rank } \\
\hline & 1 & 2 & 3 & 4 & 5 \\
\hline$S$, temperature & $0.35(0.03,0.67)$ & & $0.39(0.06,0.72)$ & & $0.30(-0.02,0.63)$ \\
\hline$S$, spring flow & $0.39(0.15,0.64)$ & $0.41(0.21,0.62)$ & $0.36(0.06,0.66)$ & $0.43(0.18,0.67)$ & $0.42(0.15,0.69)$ \\
\hline$S$, change in flow & $0.27(-0.14,0.68)$ & $0.13(-0.11,0.36)$ & $0.28(-0.15,0.71)$ & $0.13(-0.10,0.37)$ & $0.28(-0.13,0.69)$ \\
\hline$S$, turbidity & $0.10(-0.33,0.54)$ & & $0.07(-0.38,0.52)$ & & $0.08(-0.32,0.49)$ \\
\hline$\gamma$,", turbidity & $0.54(0.35,0.73)$ & $0.49(0.31,0.68)$ & $0.52(0.32,0.72)$ & $0.49(0.30,0.68)$ & $0.54(0.34,0.74)$ \\
\hline$\gamma^{\prime \prime}$, dissolved oxygen & $-0.38(-0.56,-0.20)$ & $-0.32(-0.49,-0.14)$ & $-0.40(-0.60,-0.21)$ & $-0.31(-0.50,-0.12)$ & $-0.36(-0.56,-0.16)$ \\
\hline$\gamma^{\prime}$, turbidity & $0.15(-0.07,0.36)$ & $0.10(-0.12,0.31)$ & $0.06(-0.29,0.41)$ & & \\
\hline$\gamma^{\prime}$, dissolved oxygen & $-0.23(-0.52,0.06)$ & $-0.17(-0.44,0.09)$ & & & \\
\hline$\gamma^{\prime}$, spring flow & & & $-0.25(-0.61,0.11)$ & $-0.13(-0.44,0.19)$ & $-0.15(-0.49,0.19)$ \\
\hline$\gamma^{\prime}$, change in flow & & & $0.05(-0.31,0.41)$ & $0.07(-0.17,0.31)$ & $0.11(-0.12,0.34)$ \\
\hline$\gamma^{\prime}$, temperature & & & $0.20(-0.01,0.41)$ & & \\
\hline
\end{tabular}


Figure 1

An adult Barton Springs salamander (Eurycea sosorum) moving amongst moss in Eliza Spring.

Photo Credit: Nathan Bendik, City of Austin.

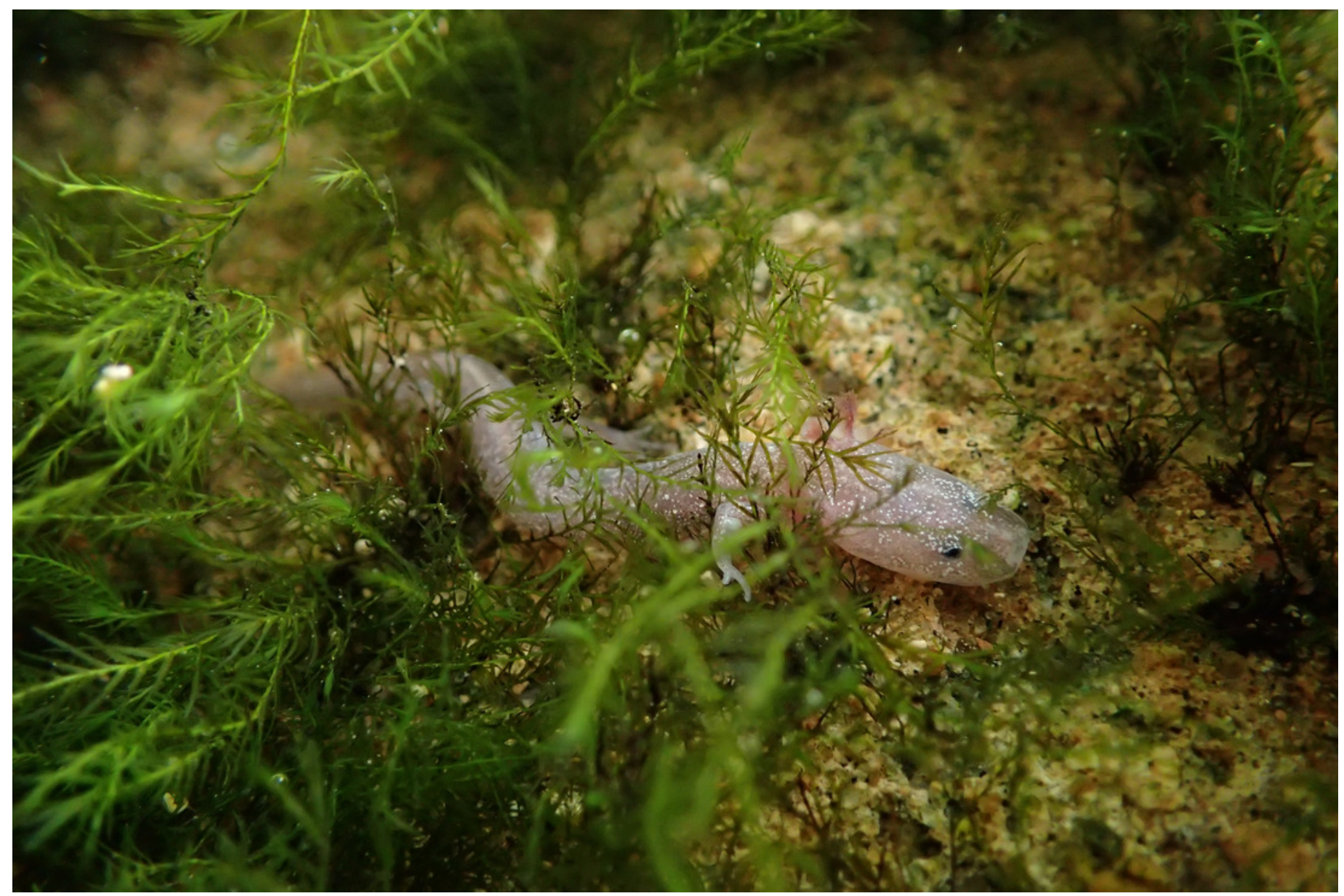


Figure 2

Eliza Spring before (A) and after (B) overland stream reconstruction.

The black circle indicates the location of the outflow drain (A) that was daylighted (B). The new overland stream (B) now flows into the bypass tunnel (underneath the sidewalk) alongside Barton Springs Pool. Photo Credit: City of Austin.

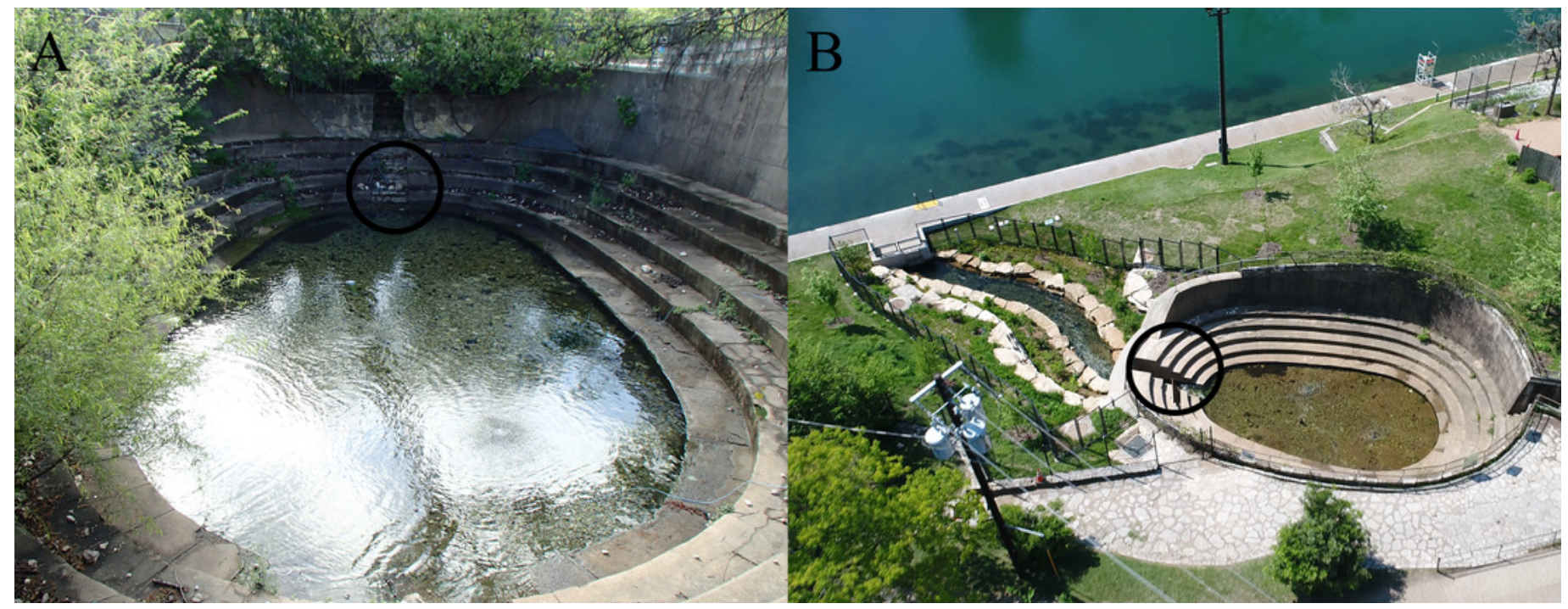




\section{Figure 3}

Growth of Barton Springs salamanders

(A) Measured growth in body length of 16 Barton Springs salamanders at different capture intervals. (B) Expected size for salamanders $>14 \mathrm{~mm}$ body length during the first year of growth based on a von Bertalanffy growth model. The dark solid line indicates age-at-length estimated from the mean parameter values for $a$ and $k$. Light gray lines are from 30 randomly generated growth curves from the mean parameter estimates to demonstrate individual variation. 

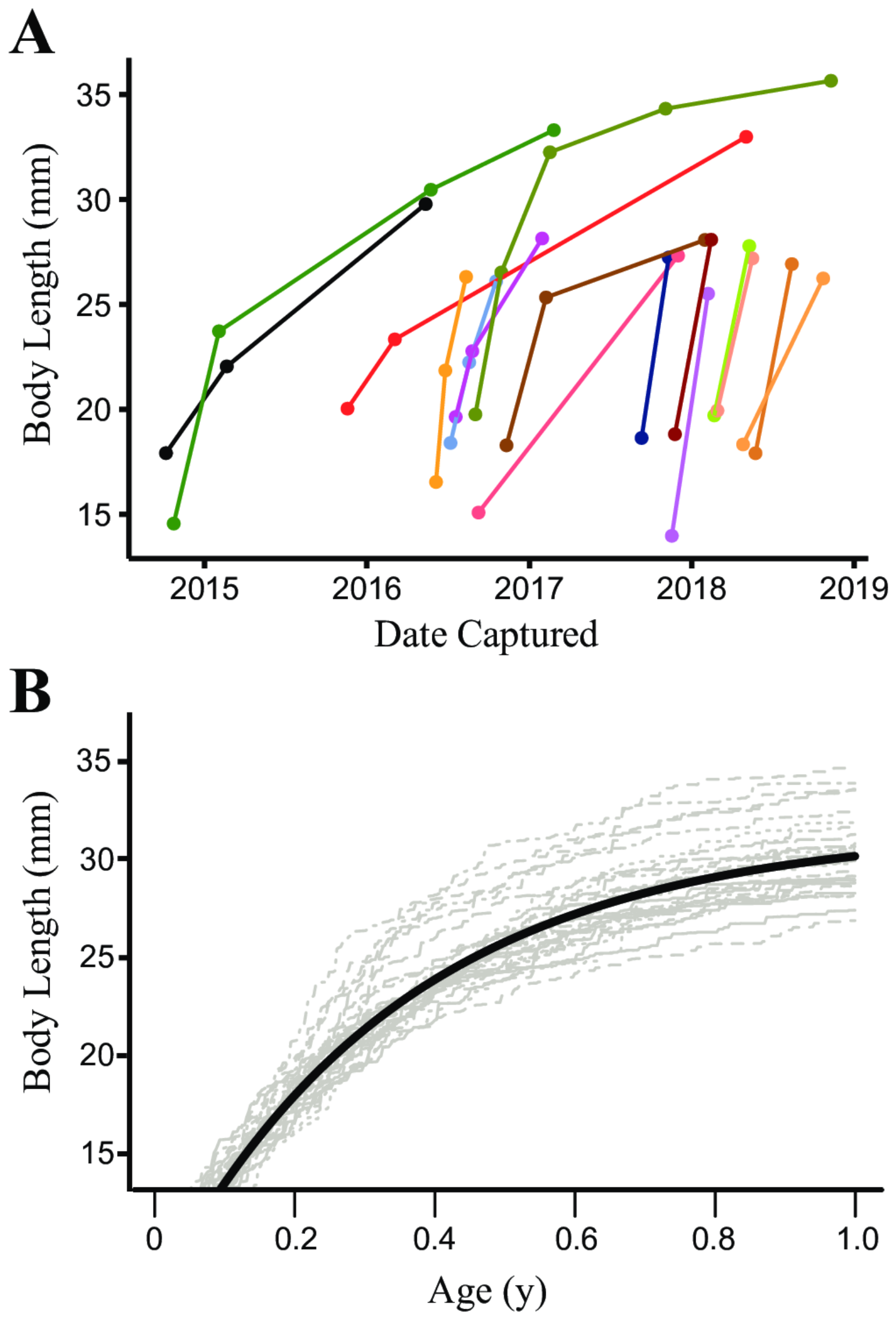


\section{Figure 4}

Model-averaged estimates of monthly apparent survival and temporary emigration.

(A) Apparent survival (B) $\gamma^{\prime}=$ unavailable at the surface | unavailable during the last survey

(C) $y^{\prime \prime}=$ unavailable at the surface | present during the last survey. Dark blue indicates

estimates for juvenile and small adults (15.01-24.20 mm body length); light orange indicates large adults (> $24.20 \mathrm{~mm})$. 

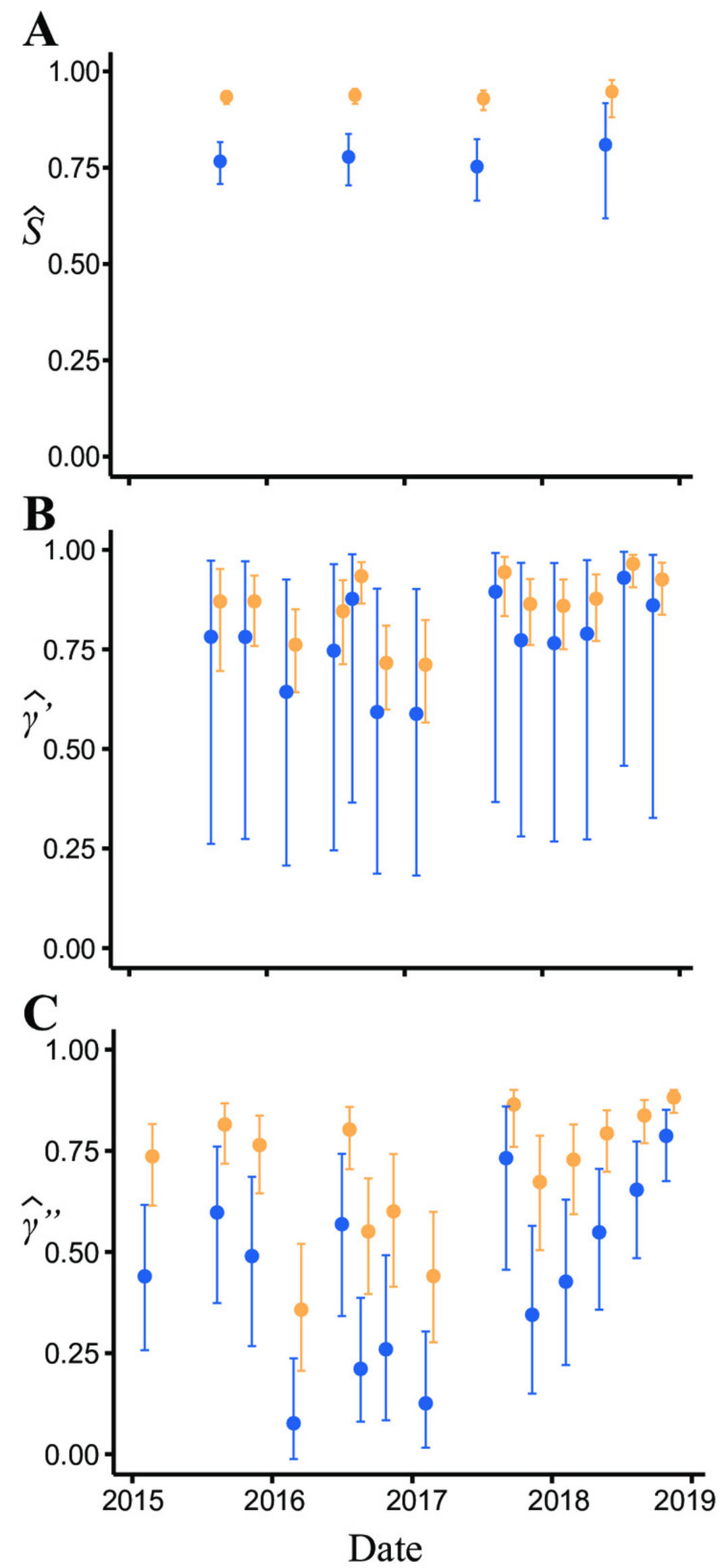

Peer] reviewing PDF | (2020:12:55968:1:0:NEW 25 Feb 2021) 
Figure 5

Abundance of Barton Springs salamanders at the surface of Eliza Spring from October, 2014 through November, 2018

Error bars represent 95\% confidence intervals.

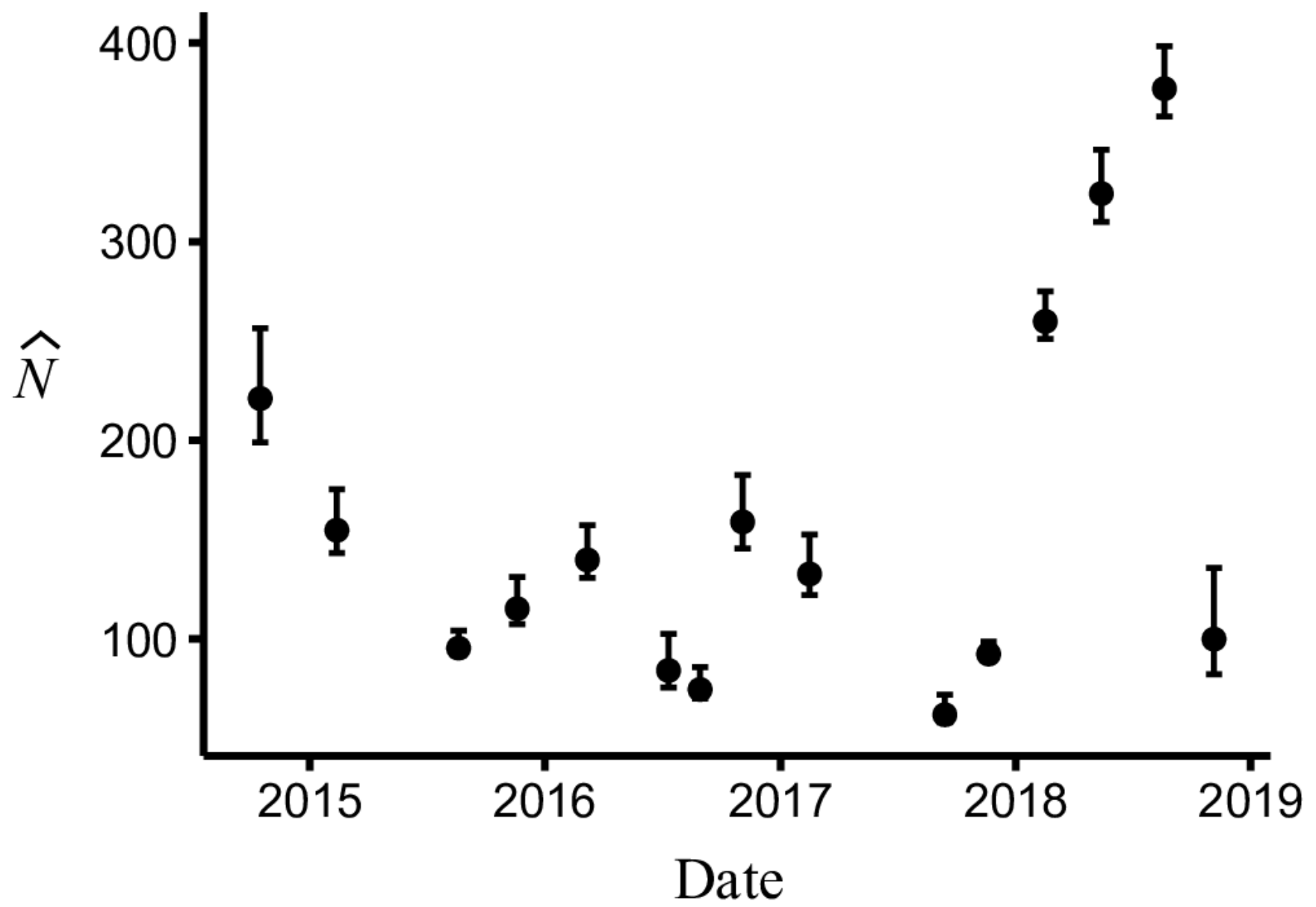

